\title{
Damned if you monitor, damned if you don't: medical malpractice and intraoperative neuromonitoring for spinal surgery
}

\author{
Jeffrey Hatef, MD, ${ }^{1}$ Miki Katzir, MD, ${ }^{1,5}$ Nathaniel Toop, MD, ${ }^{1}$ Monica Islam, MD, ${ }^{2}$ Trevor Clark, JD, ${ }^{3}$ \\ Catherine Roscoe, JD, ${ }^{3}$ Safdar Khan, MD, ${ }^{4}$ and Ehud Mendel, MD, MBA ${ }^{1,5}$
}

\begin{abstract}
1Department of Neurological Surgery, The Ohio State University Wexner Medical Center; ${ }^{2}$ Section of Child Neurology, Department of Pediatrics, Nationwide Children's Hospital and The Ohio State University; ${ }^{3}$ Associate General Counsel, Office of Legal Affairs and Risk Management, The Ohio State University Wexner Medical Center; ${ }^{4}$ Division of Spine Surgery, Department of Orthopaedic Surgery, The Ohio State University Wexner Medical Center; and ${ }^{5}$ Department of Neurological Surgery, The Ohio State University Wexner Medical Center, The James Cancer Hospital and Solove Research Institute, Columbus, Ohio
\end{abstract}

OBJECTIVE The aim of this study was to identify trends in medical malpractice litigation related to intraoperative neuromonitoring.

METHODS The Westlaw Edge legal research service was queried for malpractice litigation related to neuromonitoring in spine surgery. Cases were reviewed to determine if the plaintiff's assertion of negligence was due to either failure to use neuromonitoring or negligent monitoring. Comparative statistics and a detailed qualitative analysis of the resulting cases were performed.

RESULTS Twenty-six cases related to neuromonitoring were identified. Spinal fusion was the procedure in question in all cases, and defendants were nearly evenly divided between orthopedic surgeons and neurosurgeons. Defense verdicts were most common (54\%), followed by settlements $(27 \%)$ and plaintiff verdicts (19\%). Settlements resulted in a mean $\$ 7,575,000$ damage award, while plaintiff verdicts resulted in a mean $\$ 4,180,213$ damage award. The basis for litigation was failure to monitor in $54 \%$ of the cases and negligent monitoring in $46 \%$. There were no significant differences in case outcomes between the two allegations of negligence.

CONCLUSIONS The use and interpretation of intraoperative neuromonitoring findings can be the basis for a medical malpractice litigation. Spine surgeons can face malpractice risks by not monitoring when required by the standard of care and by interpreting or reacting to neuromonitoring findings inappropriately.

https://thejns.org/doi/abs/10.3171/2020.8.FOCUS20580

KEYWORDS neuromonitoring; malpractice; negligence; litigation; failure to monitor; negligent monitoring

I NTRAOPERATIVE neuromonitoring (ION) refers to a group of technologies used by surgeons to evaluate the function of the nervous system in real time during surgery. ${ }^{1}$ In spinal surgery, ION typically refers to the use of somatosensory evoked potentials (SSEPs), motor evoked potentials (MEPs), and electromyography to analyze the function of the spinal cord and nerve roots. The requested neuromonitoring service relies on a plan tailored for the procedure and on communication of findings between the monitoring team (technologist and neurophysiologist) and the surgeon. Among other variables, changes in waveforms may arise in relation to mechanical or vascular compromise accompanying surgical maneuvers; systemic changes affecting blood pressure, blood volume, or anesthesia; or technical difficulties. Depending on the timing and source of critical findings, the changes may be reversible or irreversible. ${ }^{2}$ Although first used regularly in spinal deformity surgeries placing the thoracic spinal cord at risk, ION use has increased with frequent use in posterior lumbar surgeries and anterior cervical fusion, and continued use

ABBREVIATIONS ION = intraoperative neuromonitoring; MEP = motor evoked potential; SSEP = somatosensory evoked potential.

SUBMITTED June 30, 2020. ACCEPTED August 20, 2020.

INCLUDE WHEN CITING DOI: 10.3171/2020.8.FOCUS20580. 
in thoracolumbar anterior and posterior spinal fusion for spinal deformities, including three-column osteotomies. ${ }^{3-7}$

ION presents the spinal surgeon with two possibilities for malpractice litigation: insufficient monitoring in cases in which it was merited or negligent monitoring in cases in which ION was used. ${ }^{8}$ As in all malpractice cases, proving liability in ION cases requires that the plaintiff prove 1) the physician had the duty to use and properly interpret ION in the particular case, 2) that duty was in some way breached, 3) the patient was harmed, and 4) the established harm was caused by the breach in duty. ${ }^{9}$ The duty a patient is owed is the standard of care, that is, the medical treatment that a reasonable physician of the same specialty would provide a patient under similar circumstances. The standard of care is established at trial by testimony of expert witnesses; ultimately, the question of what the standard of care is for a particular situation and if the standard has been met is decided by a jury.$^{10} \mathrm{~A}$ plaintiff can establish liability only by proving all four elements of malpractice, whereas a defendant can exculpate him- or herself by proving the plaintiff deficient in any one element. ${ }^{11}$

Although malpractice litigation has been the subject of previous reports in the spine surgery literature, ${ }^{12-15}$ the effect of proper use and interpretation of ION on medical negligence has not been analyzed. We analyzed medical malpractice cases in a major legal research service that focused on ION. We present our findings with specific attention to any differences between malpractice cases arising from failure to monitor and those arising from negligent monitoring. A detailed discussion of potential negligence in cases involving ION follows.

\section{Methods}

The Westlaw Edge (Thompson Reuters) legal research service was utilized to search for jury verdicts and settlements in the United States related to ION in spine surgery. The following search terms were used to query Westlaw: "neuromonitoring," "neuro monitoring," "evoked potential," "somatosensory," "SSEP," and "MEP." Cases were reviewed to determine if the assertion of negligence was related to ION. Cases were reviewed to determine the age and sex of the plaintiff, the specialty of the defendant, the type and location of the spinal surgery, the complication or poor outcome that occurred due to surgery, and the nature of the allegation of negligence. The breach of standard of care was grouped into two categories: failure to monitor and negligent monitoring. Cases were categorized as failure to monitor if the plaintiff asserted that neuromonitoring was not used when the standard of care demanded it. Cases were categorized as negligent monitoring if the plaintiff asserted that the surgeon's use or interpretation of neuromonitoring findings was below the standard of care; the most common allegation of negligent monitoring was failing to respond appropriately to critical changes in waveforms. The disposition of the case and the damages awarded to the plaintiff, if any, were recorded. Comparisons were made between cases involving failure to monitor and those involving negligent monitoring, using t-tests for numerical variables and chi-square tests for categorical variables. Statistical analysis was performed
TABLE 1. Baseline plaintiff demographics for cases involving ION in the Westlaw legal database

\begin{tabular}{cc}
\hline \multicolumn{1}{c}{ Variable } & Value \\
\hline Mean age in yrs (SD) & $52.3(18.3)$ \\
\hline Sex (\% male) & 69.2 \\
\hline Specialty* & $12(46.2)$ \\
\hline Orthopedic surgery & $15(57.7)$ \\
\hline Neurosurgery & $9(34.6)$ \\
\hline Procedure & $11(42.3)$ \\
\hline Anterior fusion & $6(23.1)$ \\
\hline Posterior fusion & $12(46.2)$ \\
\hline $360^{\circ}$ fusion & $7(26.9)$ \\
\hline Spinal location† & $11(42.3)$ \\
\hline Cervical & \\
\hline Thoracic & $5(19.2)$ \\
\hline Lumbar & $2(7.7)$ \\
\hline Complication & $11(42.3)$ \\
\hline Nerve root injury & $8(30.8)$ \\
\hline Hemiplegia & $14(53.8)$ \\
\hline Paraplegia & $12(46.2)$ \\
\hline Quadriplegia & \\
\hline Breach of standard of care & \\
\hline Failure to monitor & \\
\hline Negligent monitoring & \\
\hline
\end{tabular}

Values represent the number of cases (\%) unless stated otherwise.

* Includes 1 case with both an orthopedic surgeon and a neurosurgeon.

† Surgeries could involve more than one spinal location.

using SPSS software (IBM SPSS Statistics for Mac, version 25.0, released 2017, IBM Corp.). The analysis was reviewed by a university biostatistician to ensure rigor.

\section{Results}

Queried search terms yielded 110 total cases, with 26 cases involving ION from 1997 to 2019 identified. Cohort demographics and case information are displayed in Table 1: the average age was 52.3 years, and $69 \%$ of cases involved male plaintiffs. Defendant specialty was nearly evenly divided between neurosurgery (58\%) and orthopedic surgery (46\%), with 1 case involving both a neurosurgeon and an orthopedic surgeon. Overall, $35 \%$ of cases involved anterior spinal fusion, $42 \%$ involved posterior spinal fusion, and 23\% involved circumferential fusion surgery. Cervical and lumbar cases were more common, accounting for $46 \%$ and $42 \%$ of the cases, respectively, while the thoracic spine was involved in $27 \%$ of cases. Cases were evenly split between single- and multilevel surgeries. Paraplegia (42\%) and quadriplegia (31\%) were the most common adverse outcomes, followed by nerve root injury (19\%) and hemiplegia (8\%).

Defense verdicts were delivered by juries in $54 \%$ of cases, with $\$ 0$ damages awarded to plaintiffs (Table 2). Settlements were the next most common, accounting for $27 \%$ of cases. The mean damages awarded to plaintiffs in settlements was $\$ 7,575,000$, ranging from $\$ 600,000$ 
TABLE 2. Outcome data for legal cases involving ION

\begin{tabular}{lcccc}
\hline & No. of & \multicolumn{3}{c}{ Damage Award, \$ } \\
\cline { 3 - 5 } Outcome & $(\%)$ & Mean \pm SD & Low & High \\
\hline $\begin{array}{l}\text { Defense } \\
\text { verdict }\end{array}$ & $14(53.8)$ & 0 & 0 & 0 \\
\hline $\begin{array}{l}\text { Plaintiff } \\
\text { verdict }\end{array}$ & $5(19.2)$ & $4,180,213(4,431,297)$ & 761,819 & $11,716,118$ \\
\hline Settlement & $7(26.9)$ & $7,575,000(4,431,297)$ & 600,000 & $28,000,000$ \\
\hline Overall & $26(100)$ & $2,654,042(6,035,486)$ & 0 & $28,000,000$ \\
\hline
\end{tabular}

to $\$ 28,000,000$. Plaintiff verdicts were the least common outcome, accounting for $19 \%$ of cases. Damages awarded with a plaintiff verdict were lower than settlements, with a mean of $\$ 4,180,213$ (range \$761,819-\$11,716,118), although the difference was not statistically significant (ttest, $\mathrm{p}=0.516$ ).

Failure to monitor was the allegation of negligence in $54 \%$ of cases and negligent monitoring in $46 \%$. There were no material differences between cases involving failure to monitor and those involving negligent monitoring (Table 3). Specifically, age, sex, specialty, procedure location and type, complication, case disposition, or damages awarded did not differ significantly between the two groups.

\section{Discussion}

In 26 medical malpractice cases involving ION, 54\% of cases involved failure to monitor and $46 \%$ involved negligent monitoring. Defense verdicts were most common (54\%), followed by settlements $(27 \%$, mean damages awarded $\$ 7,575,000)$ and plaintiff verdicts $(19 \%$, mean damages awarded $\$ 4,180,213)$. There were no differences comparing cases involving failure to monitor and those involving negligent monitoring. To our knowledge, this is the first study specifically analyzing medical malpractice outcomes in cases alleging negligence involving ION.

Previous authors have analyzed malpractice cases involving spinal surgery, and our results compare similarly with published findings. Daniels et al. found a similar percentage of defendant and plaintiff verdicts, publishing a $54 \%$ rate for defendant verdict, $26 \%$ for plaintiff verdict,

TABLE 3. Statistical analysis comparing cases involving failure to monitor with those involving negligent monitoring

\begin{tabular}{|c|c|c|c|}
\hline Variable & Failure to Monitor & Negligent Monitoring & $\mathrm{p}$ Value \\
\hline Mean age in yrs (SD) & $50.0(18.0)$ & $54.5(19.4)$ & $0.609^{*}$ \\
\hline Mean plaintiff damage award in \$ (SD) & $1,950,000(70,710)$ & $5,667,022(5,566,016)$ & $0.609^{*}$ \\
\hline Mean settlement damage award in \$ (SD) & $9,487,500(12,781,912)$ & $3,750,000(2,474,873)$ & $0.436^{*}$ \\
\hline Male sex & $9(64.3)$ & $9(75)$ & $0.555 \dagger$ \\
\hline Specialty & & & $0.671 \dagger$ \\
\hline Orthopedic surgery & $7(50)$ & $5(41.7)$ & \\
\hline Neurosurgery & $7(50)$ & $7(58.3)$ & \\
\hline \multicolumn{4}{|l|}{ Procedure } \\
\hline Anterior fusion & $6(42.9)$ & $3(25)$ & $0.340 \dagger$ \\
\hline Posterior fusion & $6(42.9)$ & $5(41.7)$ & $0.951 \dagger$ \\
\hline $360^{\circ}$ fusion & $2(14.3)$ & $4(33.3)$ & $0.250 \dagger$ \\
\hline \multicolumn{4}{|l|}{ Spinal location§ } \\
\hline Cervical & $6(42.9)$ & $6(50)$ & $0.716 \dagger$ \\
\hline Thoracic & $5(35.7)$ & $2(16.7)$ & $0.275 \dagger$ \\
\hline Lumbar & $6(42.9)$ & $5(41.7)$ & $0.951 \dagger$ \\
\hline \multicolumn{4}{|l|}{ Complication } \\
\hline Nerve root injury & $4(28.6)$ & $1(8.3)$ & $0.192 \dagger$ \\
\hline Hemiplegia & $1(7.1)$ & $1(8.3)$ & $0.910 \dagger$ \\
\hline Paraplegia & $5(35.7)$ & $6(50)$ & $0.462 \dagger$ \\
\hline Quadriplegia & $4(28.6)$ & $4(33.3)$ & $0.793 \dagger$ \\
\hline \multicolumn{4}{|l|}{ Case outcome } \\
\hline Defense verdict & $7(50)$ & $7(58.3)$ & $0.671 \dagger$ \\
\hline Plaintiff verdict & $2(14.3)$ & $3(25)$ & $0.490 \dagger$ \\
\hline Settlement & $5(35.7)$ & $2(16.7)$ & $0.275 \dagger$ \\
\hline
\end{tabular}


and $19 \%$ for settlement. ${ }^{13}$ Similarly, an analysis of cases involving incidental durotomy found that $56 \%$ of cases had a defendant verdict. ${ }^{14}$ Daniels et al. found that catastrophic complications were associated with more frequent plaintiff verdicts and higher damages; ${ }^{13}$ although our study was too small to identify similar trends, catastrophic complications (paraplegia or quadriplegia) were present in nearly $75 \%$ of patients in our series.

\section{Failure to Monitor}

A malpractice case alleging failure to monitor arises when a plaintiff claims a surgeon performed a procedure wherein the standard of care required ION be used but the surgeon failed to use appropriate neuromonitoring. To meet the requirements for proving negligence, a plaintiff must prove that the injury in question was caused by the failure to monitor. ${ }^{8}$ If the standard of care did not require monitoring, or the plaintiff's injury was not proximately due to the failure to monitor, the plaintiff will fail to prove negligence. Although various surgical societies, including the Scoliosis Research Society ${ }^{16}$ and the American Association of Neurological Surgeons/Congress of Neurological Surgeons Joint Section on Disorders of the Spine and Peripheral Nerves, ${ }^{17}$ have published statements commenting on indications for ION, as discussed above, ultimately in a court of law, the question of whether ION should have been used will reside with a jury. ${ }^{10}$

Closer examination of jury verdicts in cases involving failure to monitor is instructive. Kingsley $v$ Pinto arose when, in 2004, plaintiff Kingsley woke with paralysis after a spine surgeon performed anterior and posterior spinal fusion from T3 to L2 in a single setting without ION. ${ }^{18}$ It was determined that the cause of paralysis was infarction of the spinal cord. Kingsley alleged that if ION had been used, the complication could have been avoided. The defense maintained that the plaintiff could not identify at which point in the procedure the injury occurred and could not prove that ION would have prevented it. ${ }^{8}$ The jury returned a defense verdict, although the court did acknowledge that the hospital had the necessary equipment for ION and it was likely the standard of care. Although the case is informative in that all elements of negligence must be proved by the plaintiff, we believe that it is highly likely that a current case involving similar circumstances would result in a plaintiff verdict. ION is well established as the standard of care in thoracolumbar fusion surgeries, particularly anterior spinal fusion involving segmental artery ligation with attendant risk of vascular injury. ${ }^{19}$

In other cases, juries have been more willing to agree with plaintiffs' theories regarding harm from lack of monitoring. A case involving failure to use ION during anterior cervical corpectomy, with resultant migration of the graft into the spinal cord, resulted in a plaintiff verdict and damages awarded in the amount of $\$ 7,904,000$ that were ultimately reduced to $\$ 2,095,000$ by an in-trial settlement. ${ }^{20}$ Expert witnesses in that case testified that if monitoring had been used, the graft dislodgment likely would have been diagnosed and reversed during surgery. In a second case involving a plaintiff verdict, a 63-yearold female with rheumatoid arthritis underwent C1-2 fusion with neuromonitoring. ${ }^{21}$ However, waveforms were not monitored for 56 minutes, reportedly during the time when monopolar electrocautery was used. The patient awoke quadriparetic. Although it could not be proved that the patient injury occurred during that specific time interval, plaintiff witnesses argued that it was outside the standard of care to perform such a surgery without continuous monitoring, and that may have led to the patient injury. The jury agreed and delivered a plaintiff verdict with $\$ 2,000,000$ in damages awarded. A similar case involved an L2-3 anterior and posterior fusion, with resultant nerve root injury and permanent foot drop. ${ }^{22}$ In that case, although the plaintiff argued that lack of monitoring during exposure led to the injury, the defense maintained that monitoring was appropriate and the injury occurred later in the surgery and was a known complication of the surgery. The jury in that case returned a defense verdict.

Although the individual details of the cases differ, we can glean important points from this analysis. The burden of proof for the plaintiff remains high, with defense verdicts in $50 \%$ of cases involving failure to monitor in our series. However, juries seem less willing to accept a second complication and resultant injury if monitoring is not used, with plaintiff verdicts or settlements in cases involving graft dislodgment, ${ }^{20}$ cauda equina injury from an instrument, ${ }^{23}$ and cord injury during anterior cervical fusion, ${ }^{24,25}$ any one of which could potentially be viewed by a jury as a known complication of spine surgery. Although any one of those injuries could have potentially occurred while operating within the standard of care, the lack of monitoring was a key finding that led to defense losses. There are multiple studies questioning the utility of ION in single-level cervical and lumbar surgeries, and it is up to the expert witnesses in the case to show the standard of care. ${ }^{3,26,27}$ Although a plaintiff still must prove that the lack of monitoring led to an injury, it is likely that expert witness could be introduced, maintaining use of ION as the standard of care in many, if not all, of these instances. It behooves the operating surgeon to ensure that, if ION is regarded as the standard of care for a particular surgery, it is used.

\section{Negligent Monitoring}

Once the decision to use ION is made, all parties involved are legally responsible for its proper use and interpretation and ensuring that adequate actions are taken in response to changes. In our opinion, proving malpractice due to negligent monitoring is more difficult for the plaintiff than in cases involving failure to monitor. A plaintiff must prove that a surgeon's actions in response to changes in ION, or lack thereof, were the proximate cause of injury. As with failure to monitor, analysis of case outcomes is edifying.

Two cases involved anterior cervical fusions with critical changes in waveforms. ${ }^{28,29}$ The plaintiffs argued that the cases should have been aborted at that time to allow for the maximal change at recovery. In both cases, defendants argued that as the discectomy and corpectomy had been completed at the time of signal loss, the spine was unstable and the surgery had to be completed. Defense verdicts were delivered in both cases. Similarly, in cases involving anterior and posterior cervical decompressions with loss 
of signal during the decompression, defendants argued successfully that the loss of signal was due to underlying severe stenosis, and it was more harmful to abort surgery before the spinal cord was adequately decompressed..$^{30,31}$

Only 2 cases involved plaintiff verdicts. In both cases, pedicle screws were misplaced and crossed the spinal canal. In one case, it was determined that the surgeon did not address the changes in neuromonitoring, ${ }^{32}$ while in the second case it was determined that the surgeon was primarily responsible for the interpretation of the neuromonitoring waveforms, which he neglected to do. ${ }^{33} \mathrm{In}$ both cases, the surgeons did not make any documented attempt to identify the cause of the ION change or reverse it. It seems that if surgeons take steps to rectify changes in ION, juries are more willing to accept that a poor outcome is within the standard of care.

\section{Limitations}

There are a number of limitations to our findings. Although previous authors have found malpractice litigation related to spine surgery to be common (for example, 98 cases were reviewed by Agarwal et al. ${ }^{12}$ ), we were only able to find 26 cases in which allegations of negligence were related to ION. Additionally, cases from only a single legal research service may not be representative of malpractice litigation throughout the country. However, despite these limitations, our data indicate that spinal surgeons may be liable to malpractice claims related to failing to use and negligent use of neuromonitoring.

\section{Conclusions}

In 26 medical malpractice cases involving ION, there was a nearly even split between cases arising due to allegations of failure to monitor and those arising from negligent monitoring. Defense verdicts were seen in $54 \%$ of cases, settlements in $27 \%$, and plaintiff verdicts in $19 \%$. Mean damages awarded from settlements were higher than in plaintiff verdicts, although the difference was not statistically significant. There were no significant differences in outcomes comparing failure to monitor with negligent monitoring. Neurosurgeons can face malpractice risk by not monitoring when required by the standard of care and by interpreting or reacting to neuromonitoring findings inappropriately.

\section{References}

1. Malhotra NR, Shaffrey CI. Intraoperative electrophysiological monitoring in spine surgery. Spine (Phila Pa 1976). 2010;35(25):2167-2179.

2. Legatt AD, Emerson RG, Epstein CM, et al. ACNS guideline: transcranial electrical stimulation motor evoked potential monitoring. J Clin Neurophysiol. 2016;33(1):42-50.

3. Cole T, Veeravagu A, Zhang M, et al. Intraoperative neuromonitoring in single-level spinal procedures: a retrospective propensity score-matched analysis in a national longitudinal database. Spine (Phila Pa 1976). 2014;39(23):1950-1959.

4. Xu R, Ritzl EK, Sait M, et al. A role for motor and somatosensory evoked potentials during anterior cervical discectomy and fusion for patients without myelopathy: analysis of 57 consecutive cases. Surg Neurol Int. 2011;2:133.

5. Lau D, Dalle Ore CL, Reid P, et al. Utility of neuromonitor- ing during lumbar pedicle subtraction osteotomy for adult spinal deformity. J Neurosurg Spine. 2019;31(3):397-407.

6. Huang ZF, Chen L, Yang JF, et al. Multimodality intraoperative neuromonitoring in severe thoracic deformity posterior vertebral column resection correction. World Neurosurg. 2019;127:e416-e426.

7. Strike SA, Hassanzadeh H, Jain A, et al. Intraoperative neuromonitoring in pediatric and adult spine deformity surgery. Clin Spine Surg. 2017;30(9):E1174-E1181.

8. Brook M, Irie K. Litigating intraoperative neuromonitoring (IOM). Univ Baltimore Law Rev. 2016;45(3):443-482.

9. Ogla Wiley and Antley Wiley, Plaintiffs-Appellees, $v$ Henry Ford Cottage Hospital, an assumed name for Henry Ford Health Systems, Defendant Appellant, and John Doe, Defendant, 402668 NW 2d (257 Mich App 488 2003).

10. Bruni et al, Appellants, $v$ Tatsumi et al, Appellees, 46 Ohio St 2d 127 (Ohio 1976) 346 NE 2d 673 (Supreme Ct Ohio 1976).

11. Wischmeyer v Schanz, Wischmeyer v St Mary's Medical Center, 760536 NW 2d (449 Mich 469 1995).

12. Agarwal N, Gupta R, Agarwal P, et al. Descriptive analysis of state and federal spine surgery malpractice litigation in the United States. Spine (Phila Pa 1976). 2018;43(14):984-990.

13. Daniels AH, Ruttiman R, Eltorai AEM, et al. Malpractice litigation following spine surgery. J Neurosurg Spine. 2017;27(4):470-475.

14. Durand WM, Eltorai AEM, Shantharam G, et al. Medical malpractice claims following incidental durotomy due to spinal surgery. Spine (Phila Pa 1976). 2018;43(13):940-945.

15. Makhni MC, Park PJ, Jimenez J, et al. The medicolegal landscape of spine surgery: how do surgeons fare? Spine $J$. 2018;18(2):209-215.

16. Neuromonitoring Information Statement: SRS Information Statement, 2019. Scoliosis Research Society. July 2019. Accessed September 14, 2020. https://www.srs.org/about-srs/ quality-and-safety/position-statements/neuromonitoringinformation-statement

17. AANS/CNS Joint Section on Disorders of the Spine and Peripheral Nerves Updated Position Statement: Intraoperative Electrophysiological Monitoring. SpineSection. org. January 2018. Accessed September 14, 2020. https:// www.spinesection.org/statement-detail/intraoperativeelectrophysiological-monitoring

18. Kingsley v Pinto, 2010 WL 3591538 (Dist Ct Minn, Fourth Judicial Dist, Hennepin Cnty 2010).

19. Dormans JP. Establishing a standard of care for neuromonitoring during spinal deformity surgery. Spine (Phila $\mathrm{Pa}$ 1976). 2010;35(25):2180-2185.

20. Marcel \& Roseanne Paul v NY Methodist Hospital Harald Fodstad MD, Victor Ho MD, University Neuroscience Group and Roland P Ottley PA, 2008 WL 2581476 (Supreme $\mathrm{Ct}$, Second Judicial Dist, Kings Cnty, NY 2008).

21. Jorge Navarrete v Michael Alexiades MD et al., $27 \mathrm{NY}$ JVRA. 4:C4, 2009 WL 9053604 (Supreme Ct, Eleventh Judicial Dist, Queens Cnty, NY 2009).

22. Strand v Knight MD; Orthopedics International, JVR No 1312060010, 2013 WL 6384492 (Super Ct Wash, King Cnty 2013).

23. Billy Smith and Cindy Smith v Baxano Inc.; Dr Wu Zhuge; Kruger Clinic; Swedish Hospital and Medical Center and its agents Dr. Bjorn Krane; and Northwest Neurodiagnostics, 15 NWPI Lit Rpts 47, 2014 WL 8103740 (Super Ct Wash, Snohomish Cnty 2014).

24. Bradford Hensley and Cara Hensley v Multicare Health Systems Inc, 20 Or Lit Arb Rpts 81, 2019 WL 8724070 (Super Ct Wash, Pierce Cnty 2019).

25. Mensik v Small, 2009 WL 3469943 (Dist Ct Tex, 281st Judicial Dist, Harris Cnty 2009).

26. Ajiboye RM, D’Oro A, Ashana AO, et al. Routine use of 
intraoperative neuromonitoring during $\mathrm{ACDF}$ for the treatment of spondylotic myelopathy and radiculopathy is questionable: a review of 15,395 cases. Spine (Phila Pa 1976). 2017;42(1):14-19.

27. Krause KL, Cheaney Ii B, Obayashi JT, et al. Intraoperative neuromonitoring for one-level lumbar discectomies is low yield and cost-ineffective. J Clin Neurosci. 2020;71:97-100.

28. Collier v Resurgens PC, 2011 WL 6093386 (Ga Super Ct, Atlanta Judicial Circuit, Fulton Cnty 2011).

29. Chen vs Sheinberg, 16 Trials Digest 8th 10, 2005 WL 894686 (Super Ct, Alameda Cnty, Cal 2005).

30. Hankins v Eule MD; Orthopedic Physicians Anchorage Inc, JVR No 19010800352018 WL 6982375 (Super Ct Alaska, Third Judicial Dist 2018).

31. Cepeda MD v Walters AUD; Proler MD; Meyer L Proler $M D \&$ Associates PA D/B/A Interpeting Physicians Link; Methodist Healthcare Systems of SA Ltd LLP D/B/A Metropolitan Methodist Hospital, JVR No. 1411180026, 2014 WL 6806903 (Dist Ct Tex, Bexar Cnty; 2014).

32. Jones v Miller MD; Markey MD, JVR No 1610110006, 2016 WL 5921811 (Dist Ct Colo, Eighth Judicial Dist, Larimer Cnty 2016).
33. Ayala $v$ Friedlander et al, 38 NJ JVRA 12:C5, $1000 \mathrm{WL}$ 286025 (Super Ct NJ, Law Div, Union Cnty 2018).

\section{Disclosures}

The authors report no conflict of interest concerning the materials or methods used in this study or the findings specified in this paper.

\section{Author Contributions}

Conception and design: Hatef, Mendel. Acquisition of data: Hatef. Analysis and interpretation of data: Hatef, Toop. Drafting the article: Hatef, Katzir. Critically revising the article: Katzir, Toop, Islam, Clark, Roscoe, Khan, Mendel. Reviewed submitted version of manuscript: Mendel. Statistical analysis: Hatef. Administrative/ technical/material support: Mendel. Study supervision: Mendel.

\section{Correspondence}

Jeffrey Hatef: Ohio State University Wexner Medical Center, Columbus, OH. jeffreyjr.hatef@gmail.com. 